\title{
From Council to Commission: Whither Medical Education in India!
}

\begin{abstract}
Indian Parliament has recently enacted a law to create a new regulatory body for accreditation of medical degrees (Gazette of India). It is designated as National Medical Commission (NMC) Act-2019. It will replace the Medical Council of India (MCl) which came in existence in 1933. It will start functioning from first quarter of 2020. NMC will improve access to quality and affordable medical education, ensures availability of adequate and high quality medical professionals in all parts of the country. NMC's preamble is to improve access to quality of medical education and making it affordable to all sections of the society. It also ensures availability of adequate and high quality medical professionals in all parts of the country. Thus, it is an attempt to put an end to escalating criticism of medical education which intensified in recent decades due to role of private sector in particular! In this background, this paper dilates on the transition occurring in medical education in India.
\end{abstract}

Mathur, S. C.
India currently has a population of 1.37 billion (Worldometers.info., 2019). Ministry of Health in its National Health Profile-2018 has indicated that average population served per government allopathic doctor is 11,039 . It has brought on record 1041395 Doctors registered with $\mathrm{MCl}$ as of 2017, far from sufficient in the public health systems as per WHO norms.

Last three decades have seen a tremendous growth in the number of Medical Colleges in India and number of undergraduate seats in the same. Only 41 of the $143(28.6 \%)$ Medical Colleges were owned by private sector in 1990, since then number owned by them increased to 281 out of 539 (52.1\%) as of 2019 (Table 1).

Department of Preventive and Social Medicine, SMS

Medical College, Jaipur, India.

Corresponding Author: Professor Shiv Chandra Mathur, Professor of Community Medicine, and Public Health Consultant, India

Email: shivmathur51@gmail.com

DOI: http://doi.org/10.4038/seajme.v14i2.273
Table 2 shows the increase in the number of under-graduate (UG) seats in the Medical Colleges from 1990 to 2019. Increase in the UG medical seats was three-fold in private sector in contrast to government Medical Colleges.

Shortage of Doctors of modern Medicine in the public health system triggered the growth of Medical Colleges. Liberalisation of economy from early nineties encouraged the private players to invest and enhance the production of Doctors. National Rural Health Mission was launched throughout India in 2005 which further underscored the need of Doctors at peripheral health facilities. NRHM made provisions for the states to launch new Medical Colleges since it envisaged the need for one Medical College in each of the erstwhile 630 districts of the country.

Starting a new Medical College to deliver graduate degree (MBBS) and post-graduate courses primarily depended on the recommendation given by $(\mathrm{MCl})$ to the Ministry of Health. The $\mathrm{MCl}$ was plagued by corruption and had become the reason for the diminishing respect of medical profession in the country. $\mathrm{MCl}$ first came under severe criticism after the charges of corruption on its Chairperson with suspicious involvement of his team almost two decades back. But the power game between the Ministry of Health and the autonomous body of the Government of India pulled on for almost a decade. Initially an alternative to it was proposed as 'National Commission for Human Resources for Health' embracing all the bodies regulating different cadres of health professionals. Involvement of a wide cross section inhibited its feasibility. Thereupon steps to regulate the quality of medical education starting from convening of country-wide common entrance test for Medical Colleges to sticking to faculty and patient norms by the newly started Medical Colleges in particular were strictly initiated but they did not prove to be of as much help in delivering a desired outcome as was expected. Increasing 
litigations in the process of medical education led to hand over the regulatory functions to a Board of Governors. In the meantime a Parliamentary Standing Committee went indepth on regulating the practice of modern medicine through $\mathrm{MCl}$. Their critiquing led to the change. Thereafter highest planning forum of India (Niti Aayog) took up the responsibility to draft a bill to be discussed by both the houses of the Parliament. This bill was brought under the banner of 'National Medical Commission Bill' and passed in August 2019 as "NMC Act $-2019 ” !$

Table 1: Number of Medical colleges in India

\begin{tabular}{cccc}
\hline Year & Private & Govt. & Total \\
\hline 1990 & 41 & 102 & 143 \\
\hline 1995 & 47 & 109 & 156 \\
\hline 2000 & 61 & 115 & 176 \\
\hline 2004 & 100 & 121 & 221 \\
\hline 2006 & 131 & 131 & 262 \\
\hline 2007 & 137 & 134 & 271 \\
\hline 2013 & 205 & 176 & 381 \\
\hline 2014 & 214 & 181 & 395 \\
\hline 2015 & 222 & 200 & 422 \\
\hline 2017 & 259 & 220 & 479 \\
\hline 2019 & 258 & 281 & 539 \\
\hline
\end{tabular}

Table 2: Number of UG Seats in Medical Colleges of India

\begin{tabular}{cccc}
\hline Year & Private & Govt. & Total \\
\hline 1990 & 4785 & 11800 & 16585 \\
\hline 2019 & 43643 & 33285 & 76928 \\
\hline
\end{tabular}

NMC is altogether a new structure. Primarily NMC will be a body of 32 Commissioners under a Chairperson (an eminent medical practitioner), 10 of whom would be ex-officio members representing different apex bodies of Ministry of Health. Since the notification of the NMC Act a Medical Advisory Council has been constituted taking full care of federal polity honouring the autonomy of the state governments. This council has representation of state government as well as elected bodies of Doctors to sustain the mechanisms taking care of quality of medical education. On dayto-day basis NMC will be assisted by four autonomous boards' viz.:

1. Undergraduate Medical Education Board

2. Postgraduate Medical Education Board

3. Medical Assessment and rating Board

4. Ethics and Medical Regulation Board
Each Board will be controlled by a President with 2 whole time and 2 part-time Members who would regularly meet once a month.

The NMC will bring in changes in the way medical colleges are assessed, MBBS entrance are conducted and bring in new provisions such as entrance/ exit exams and regulation of course fees in private colleges. There will be single National Eligibility cum Entrance Test (NEET) to admit students to all medical colleges including All India Institute of Medical Sciences with a common counselling. Section 15 (1) of the NMC Act proposes a common final-year MBBS exam ${ }^{1}$, the National Exit Test (NEXT), before an individual start practising medicine. NEXT will be an exclusive consideration for seeking admission to postgraduate medical courses and for enrolment in the state register or the national register. Eventually NEXT would be primary criteria for getting a license to practice and enrol into the medical register. This component of the change was vehemently opposed albeit one of the 
major reforms in medical education with NMC. There will also be a screening test for foreign medical graduates to ensure their knowledge and skills equalise with NEXT. NMC Act has emphasised on competency-based MBBS course and skill-based training during the internship period. Thus, students can focus on internship instead of preparing for PG exams. NMC will frame guidelines for determination of fees and all other charges in respect of $50 \%$ of seats in private medical institutions and 'deemed to be' universities which are governed under the provisions of this Act.

The NMC Act-2019 is student-friendly and aims to rid medical education of vested interests that were subverting qualitative improvements in this sector. According to Union Health Minister NMC Bill, 2019 will go down in history as the biggest reform of the 21st century in the field of medical education in India. Quacks will have no role in this scheme of things and the punishment for quackery has actually been enhanced to up to one year imprisonment and fine of INR 5 lakh.

The NMC Bill simplifies procedures and eliminates repeated inspections of colleges. NMC is also mandated to reduce the cost of medical education, thereby facilitating setting up of more medical colleges. Union government has already increased 28,000 MBBS seats and 17,000 PG seats in the past five years, which is a record of sorts. Ministry of Health also requested the current Board of Governors of outgoing $\mathrm{MCl}$ to rationalise teacher-student ratio, and simplify physical infrastructure requirements of medical colleges. Union Health Minister says if we are able to maintain the trend of increasing the number of Medical Colleges and UG seats therein, then we are hopeful of achieving doctor-population ratio of 1:1000 within the next 7-8 years.

In this background author has done a SWOT of newly conceived body which is as follows:

\section{Strengths}

1. With majority of Doctors on Board, NMC isn't a burecratic body

2. NMC's monitoring is outcome focused unlike input monitoring of $\mathrm{MCl}$

3. Sustaining NEET for Medical Colleges signals the removal of bias in admission procedure

4. NEXT will determine the common standards of the products delivered around the country

5. Licentiate exam merged with NEXT will contain the cost for registering as a practitioner

\section{Weaknesses}

1. Half of UG/PG seats in private sector left at the discretion of Medical Colleges

2. Ambiguity in context of Community Health Provider continues

3. No concurrent stringency for other cadre of health professionals

4. Indian Medical Association not supporting the change whole heartedly

5. Some of the States have signaled political colour to this change

\section{Opportunities}

1. Demand and Supply of Doctors for public health systems in India can be rectified.

2. A new arena of autonomy is created to uphold the standards in the production of physicians.

3. It will contain the private players who have often adopted foul practices under $\mathrm{MCl}$ regime for seeking recognition

4. Right time to strengthen approach towards Universal Health Care and way to achieve SDG

\section{Threats}

1. Control by the Union government of Search Committee to select Chairpersons of NMC and Presidents of its Boards may tamper autonomy of NMC in long run

2. Inspections of Medical Colleges may be contracted out to private/commercial agencies.

3. Mandate of Joint Meetings with other systems sustains the anxiety of irrational and incompatible mix of different systems of Medicine.

4. Since a number of political leaders have stakes in private Medical Colleges, sincerity in implementation raises doubts!

5. Rapid growth of sub-specialities hampers the goals of UG medical education.

6. Bodies like AlIMS kept out of NMC Act may influence the morale of followers of NMC Act!

At the moment stakeholders can keep their fingers crossed on the issue of cultural change expected from NMC in more than 500 Medical Colleges of India. Strong political commitment to strengthen health sector can only pave the way for vision reflected in enhancing the quality and quantity of Doctors to be made available to peripheral health facilities! 


\section{References}

Gazette of India No. 30 of 2019 PART II Section 1 on The National Medical Commission Act, 2019 published on 8th August 2019

Nagarjun R.: What spurred ₹ $12 \mathrm{k}$ cr med ed black market in the Times of India, New Jaipur, 112 February, 2016

National Health Profile (2018) CBHI, MOHFW, Government of India, New Delhi, 2019.

Shiv Mathur: Rejuvenating Regulation of Medical Education in India, Poster presented at Global Symposium on Health Workforce Accreditation and Regulation under the aegis of WHO/ECFMG/GHWN on December 10-12, 2019 at Istanbul

Union Health Minister Harsh Vardhan speaks to Abantika Ghosh on why the NMC Bill is a historic reform Interview by Abantika Ghosh, The Hindustan Times, New Delhi, August 5, 2019

Worldometers.info. (2019). India Population (2019) - Worldometers. [online] Available at: https://www.worldometers.info/worldpopulation/india-population/ 